\title{
Influencia de las imágenes mentales generadas por la publicidad en la mente del público infantil según la naturaleza del estímulo
}

\section{Isidoro Arroyo-Almaraz' Francisco García-García²}

Recibido: 2014-03-20

Enviado a pares: 2014-03-23
Aprobado por pares: 2014-05-30

Aceptado: 2014-06-05

DOI: 10.5294/pacla.2015.18.1.9

Para citar este artículo / To reference this article / Para citar este artigo Arroyo-Almaraz, I., García-García, F. Marzo de 2015. Influencia de las imágenes mentales generadas por la publicidad en la mente del público infantil según la naturaleza del estímulo. Palabra Clave 18(1), 212-238. DOI: 10.5294/pacla.2015.18.1.9

\section{Resumen}

Las imágenes mentales que generan los anuncios tienen efectos, tanto en el recuerdo como en la evocación de respuestas en los públicos. Se ha utilizado una metodología de análisis de contenido de las palabras que intervienen en la descripción verbal escrita de las imágenes mentales evocadas a través de una tarea de recuerdo libre. Los resultados confirman que el recuerdo de la imagen mental varía en los sujetos según la modalidad de presentación del estímulo: imagen, palabra, sonido. Y un análisis multivariable de la varianza atribuye las diferencias, también, a la capacidad de viveza de imagen mental de los sujetos.

\footnotetext{
Universidad Rey Juan Carlos. España. isidoro.arroyo@urjc.es

Universidad Complutense de Madrid. España. fghenche@gmail.com
} 


\section{Palabras clave}

Publicidad, recuerdo, imágenes mentales, viveza, sexo (Fuente: Tesauro de la Unesco).

\section{Influence of Advertising-Generated Mental Images on the Minds of the Child Audience According to the Nature of the Stimulus}

\section{Abstract}

The mental images generated by advertisements and commercial ads have an effect both on the memory and on eliciting responses from the public. A methodology has been used that analyzes the content of the words involved in the verbal written description of the mental images evoked through a free recall task. The findings confirm that the remembrance of the mental images in the subjects varies according to the type of stimulus presented: image, word, sound. In the same manner, a multivariate analysis of the variance also ascribes the differences to the vividness of the mental capacity of the subjects.

\section{Keywords}

Journalism, remembrance, mental images, vividness, sex (Source: Unesco Thesaurus). 


\section{Influência das imagens mentais geradas pela publicidade na mente do público infantil de acordo com a natureza do estímulo}

\section{Resumo}

As imagens mentais que geram os anúncios têm efeitos, tanto na lembrança quanto na evocação de respostas nos públicos. Utilizou-se uma metodologia de análise de conteúdo das palavras que intervém na descrição verbal escrita das imagens mentais evocadas através de uma tarefa de recordação livre. Os resultados confirmam que a lembrança da imagem mental varia nos sujeitos de acordo com a modalidade de apresentação do estímulo: imagem, palavra, som. E uma análise multivariável da variância atribui as diferenças, também, à capacidade de viveza de imagem mental dos sujeitos.

\section{Palavras-chave}

Publicidade, recordação, imagens mentais, viveza, sexo (Fonte: Tesauro da Unesco). 


\section{Introducción}

Ha pasado más de medio siglo desde que la comunidad científica ha establecido una relación entre la imaginabilidad de los mensajes publicitarios, entendida como su capacidad para generar imágenes mentales y su efectividad en los públicos para procesar la información, estimular el recuerdo, despertar una actitud favorable hacia la marca o favorecer una intención de compra. En todo este tiempo se ha construido un amplio corpus teórico que ha puesto de manifiesto la diferente eficacia de cada uno de los elementos que componen los mensajes publicitarios: las imágenes, las palabras y los sonidos.

La diferencia de generación de imágenes mentales dependiendo de la naturaleza sensorial del estímulo se ha mostrado a través de una amplia literatura científica (Sharps \& Price, 1992; Thompson \& Paivio, 1994; Arroyo, 1997, 2006; Arroyo, Martínez-Val \& García, 2001; Zvyagintsev et al., 2013). Sabemos por ella, en primer lugar, que las imágenes se recuerdan mejor que las palabras y que su recuerdo no decrece tan rápidamente con el paso del tiempo (Arroyo, 1997). Esta ventaja de las imágenes publicitarias viene determinada por múltiples razones. En primer lugar, según la conocida teoría de codificación dual que formuló Paivio en 1971, porque facilitan el aprendizaje de palabras a través de la doble codificación, de manera que a la vez que vemos una imagen memorizamos un nombre. Por eso, los públicos recuerdan mejor las empresas o los nombres de marca después de ver una descripción en imágenes de la misma junto con el nombre de la empresa. E incluso la interacción de imágenes ayuda al sujeto a recordar mejor los dos ítems que deben ser aprendidos y los recuerda mejor que repitiéndolos por separado. Se recuerdan mejor los nombres de las empresas que tienen logotipos de interacción de imágenes que aquellos que usan logos construidos con manipulaciones o interacciones de palabras.

En segundo lugar, los mensajes publicitarios pueden comunicar más cosas con imágenes que con palabras, tanto lo referido a atributos de los productos como a conceptos abstractos. Cuando se usan imágenes para comunicar conceptos abstractos, aumenta el aprendizaje y mejoran las actitudes (Alesandrini, 1982). 
En tercer lugar, las imágenes visuales en los mensajes publicitarios, es decir la parte visual del mensaje generalmente en foto o dibujo, también pueden ser utilizadas para influir en la conducta del público a través de un aprendizaje vicario. Donova, Jancey y Jones (2002) han comprobado que los pósters de publicidad de cigarrillos en los puntos de venta incrementan la generación de imágenes mentales favorables hacia las marcas de cigarrillos y afectan a los niños entre 10 y 12 años.

Las imágenes realistas favorecen el recuerdo. La información concreta tiene más influencia en la toma de decisiones que la información abstracta porque se puede transformar más fácilmente en imágenes mentales y además estas son más referenciales con el objeto y lo representan de una manera más fidedigna. Las investigaciones indican que los públicos prefieren imágenes concretas antes que abstractas. De ahí que el realismo y la complejidad se definan como la cantidad de detalles en una imagen. La gente prefiere ver imágenes con detalles (complejas) y esa preferencia se incrementa con la edad. De acuerdo con Percy y Elliott (2005: 218), las imágenes realistas estimulan la generación de imágenes mentales: "higher imagery pictures are those that tend to arouse other mental images quickly and easily. They are more realistic than abstract, low-imagery pictures". Hay dos razones: la primera, que la gente puede obtener más detalles de las representaciones realistas que de las abstractas; la segunda, según explica la teoría dual, que la gente puede generar con más facilidad imágenes de palabras concretas y palabras de imágenes realistas, dado que cuando mostramos una imagen o decimos una palabra se evoca a la vez la palabra cuando es imagen y la imagen cuando es palabra. "Many television ads use animation, and often you see cartoons or drawings in print adverts. This can in fact be very realistic because of its simplified rendering of its subject. Using this technique can basically strip its subject to its essential denotative characters, making them very concrete" (Rossiter, 1988: 35-39).

El objeto de estudio de esta investigación consiste en conocer cómo influye la diferente naturaleza de los estímulos en la generación de imágenes mentales en las audiencias de acuerdo a sus diferencias de sexo, edad y capacidad de viveza de imagen mental. 
Las diferencias entre las capacidades que tienen los varones y las mujeres para formar imágenes mentales, indistintamente de cuál sea la tarea a realizar, cuál sea el instrumento de medida o cuál el indicador de capacidad, obtiene resultados diversos. En algunos trabajos las mujeres han obtenido mejores resultados que los hombres (Paivio \& Harshman, 1983; McKelvie, 1986; Campos \& Pérez, 1988a); en cambio, en otros trabajos no se encuentran diferencias (McConkey \& Nogrady ,1986; Campos \& Pérez ,1988b; García, 1997).

La edad del público es un factor importante que incide significativamente en la respuesta de los sujetos cuando se forma una imagen mental a partir de un estímulo, tanto icónico como auditivo-sonoro o audioverbal. De ahí la importancia que tiene la publicidad en la generación de imágenes mentales entre los niños y los adolescentes.

La edad también es un factor relevante que influye en la capacidad de recordar y reproducir nombres, ya que tiene una alta correlación con la edad de adquisición del vocabulario, porque, según Van Loon-Vervoorn y Der Ham-Van Koppen (1988), existen dos tipos de conocimiento del léxico que se adquieren a edades distintas: a) el conocimiento léxico de adquisición más temprana, que estaría basado en las interacciones sensorio-motoras que el sujeto tiene con su medio y, por tanto, tendría un fuerte componente episódi$\mathrm{co}, \mathrm{y}$ b) el conocimiento léxico de adquisición más tardía, que estaría basado en definiciones verbales, es decir condicionado por criterios lingüísticos, donde el significado de las palabras dependería del valor semántico. Es por ello que el eslogan, la frase o lema publicitario que resume y repite la idea, tiene un alto rendimiento semántico que facilita el recuerdo de cualquier producto porque es una frase fácil de recordar para el público. Existirían palabras consideradas de alta imaginabilidad, por ejemplo el eslogan "El aroma de mi hogar" o "Un Martini invita a vivir", que se procesan más fácilmente que aquellas otras consideradas de baja imaginabilidad. Por eso debemos prestar atención a qué se dice tanto en el eslogan como en el copy del anuncio, entendido como cuerpo de texto con argumentos y descripciones, ya que, según sean las palabras de alta o baja imaginabilidad, facilitarán o dificultarán la comprensión de los textos. Según Percy y Elliott (2005: 218), un concepto fundamental es el grado de concreción de las palabras: "Concrete words are 
generally described as those that refer to objects, persons, places, or things that can be experienced by the senses; those that do not are called abstract. Concrete words are more effective than abstract words in communicating ideas, and are better remembered".

Las palabras concretas facilitan la generación de imágenes mentales más rápida y fácilmente que las palabras abstractas. La frecuencia de aparición de una palabra, cuando la tarea consiste en nombrar el objeto, es también un factor que influye en la velocidad de acceso léxico en la producción de discursos, de tal manera que las palabras que aparecen en el léxico con menos frecuencia aparecen con menos rapidez para nombrar la representación pictórica de un objeto (Morrison, Ellis \& Quinlan, 1992).

Finalmente, cuando los estímulos son auditivos, o bien cuando las imágenes mentales son auditivas o visuales, y cuya fuente de información son las ocurrencias espontáneas reflejadas en informes personales, según Giambra y Grodsky (1991), tienen correlaciones negativas con la edad, de tal forma que disminuyen a medida que la edad aumenta. Así, las diferencias más grandes se han encontrado entre los sujetos con 25 años, que tienen un nivel óptimo de recuerdo en imágenes, y los de 70 años, con un nivel ínfimo de recuerdo en imágenes mentales.

De acuerdo con Percy y Elliott (2005: 237), las palabras dichas en los medios de comunicación influyen en la respuesta emotiva, tanto por su contenido como por su expresión: "In broadcast advertising or the Internet, spoken words or sound effects can be used to evoke a variety of emotional responses. With words, we are not so much concerned with their literal meanings, but the manner in which they are spoken”.

Así, el mensaje sonoro radiofónico construido con sonido envolvente 5.1 estimula más la imaginación creativa porque consigue una mayor estimulación sensorial $360^{\circ}$, capta más la atención del receptor y evita distracciones y facilita la memoria auditiva profunda, ya que nuestro cerebro guarda todos los momentos sonoros de nuestras vidas, que luego evoca a través de imágenes mentales (Sánchez, 2008). 
La viveza con que aparece una imagen mental influye también en el recuerdo de palabras asociadas. Un instrumento muy fiable que se viene utilizando ininterrumpidamente para su medida es el Vividness of Visual Imagery Questionnarie (VVIQ) de Marks (1989). Por último, la tarea de evocación escrita también influye en el recuerdo de la imagen mental. La investigación en el terreno de la psicolingüística llevada a cabo por Sánchez y García-Albea (1986) ha demostrado que los procesos de recuperación del lenguaje están organizados para permitir un acceso rápido a los códigos de representación mental. Anne-Marie Diller (1991), desde la semántica cognitiva, afirma que la riqueza y la complejidad en el dominio de una experiencia son el reflejo de las metáforas necesarias para definirla, a lo que nosotros añadiríamos, junto con Sánchez y García-Albea (1986), el valor estructural y representativo del material verbal en la memoria. Es decir, tanto las tareas de reconocimiento como las de recuperación léxica del lenguaje tienen una relación directa con el análisis de las oraciones que intervienen en el proceso expresivo y, dentro de este, con las categorías gramaticales a las que pertenecen las palabras.

Es de interés para esta investigación el uso de dos tipos de categorías gramaticales en la evocación de imágenes mentales que, según los diferentes autores, han recibido distintos nombres: Sánchez y García-Albea (1986) proponen la terminología de clase abierta y clase cerrada para referirse a los verbos, nombres y adjetivos en el primer caso, y a los pronombres, adverbios, verbos copulativos, preposiciones y artículos, en el segundo. Para estos autores el elemento diferenciador de ambas categorías era fundamentalmente la frecuencia con que las palabras aparecían, siendo las abiertas más frecuentes que las cerradas. También las denominan mayores y menores porque son más o menos relevantes, constituyen vocabularios distintos y tienen correspondencias psicológicas particulares en la forma de procesar la información verbal o de acceder a ella. Los gramáticos taxonómicos propusieron las denominaciones "palabras de contenido" y "palabras funcionales”, equivalentes a mayores y menores o abiertas y cerradas.

La primera hipótesis de esta investigación establece que una imagen será más rica cuando en su evocación escrita esté formada por un número 
mayor de palabras abiertas, que corresponden a aquellas palabras que pueden incrementar el número de sus elementos (nombres, verbos, adjetivos $\mathrm{y}$ adverbios), tanto con procedimientos gramaticales ordinarios como por ocurrencias publicitarias, como ocurre con los sustantivos, inventando nuevos nombres en sus eslóganes para evocar nuevas imágenes mentales, como, por ejemplo, "autoemoción” en el claim "Seat Toledo: autoemoción”, donde a partir de auto (uno mismo) y emoción se posiciona el automóvil Seat Toledo como un vehículo que despierta fuertes emociones (Robles, 2004), o "Tippexperience”, que surge del nombre de la marca (Tipp-Ex) y la palabra experiencia en inglés (experience). El significado que adquiere la nueva palabra conjuga la experiencia que ofrece Tipp-Ex con las connotaciones que de esta experiencia pueda adherir el público objetivo al producto que se anuncia y a la propia marca (Llorente, 2013).

Los verbos también generan imágenes mentales con procedimientos publicitarios; por ejemplo, a partir de conjugar como si fuera un verbo el nombre del producto Actimel o inventando un nuevo verbo, como ocurre en el eslogan: "nuevas natillas Danone para beber. ¡Pruebébelas! ¡Actimelízate! Actimel”.

Los adjetivos también son fuente de ocurrencias que forman nuevas palabras abiertas; por ejemplo, Mcnífico en el eslogan "nuevo menú Mcnífico de McDonald's", que vincula el adjetivo magnífico a la marca McDonald's, a partir de la homofonía. El nuevo adjetivo suena igual en español para la sílaba mag (/mak/) que para el vocablo Mc. Y, por último, los adverbios, con ejemplos como: "Posiblemente la mejor cerveza del mundo" (Carlsberg). El adverbio de modo introduce el concepto de liderazgo sin faltar por ello a la verdad.

La segunda hipótesis de esta investigación establece que una imagen será más compleja cuando en su evocación escrita esté formada por un número mayor de palabras abiertas y cerradas, que corresponden a aquellas que pertenecen a inventarios limitados (preposiciones y conjunciones), sin modificaciones posibles, ni sincrónicas ni diacrónicas. Evocar una imagen 
mental siempre es un proceso cognitivo complejo porque se trata de percibir un objeto que no está presente en el momento que lo reconstruimos (Zvyagintsev et al., 2013). Pero habitualmente el concepto de complejidad de una imagen mental en publicidad se asocia a la retórica publicitaria (Schroeder, 2008). De manera que, unas veces, se entenderá que la publicidad es compleja cuando las imágenes que genera establecen una relación indirecta entre sus mensajes y las marcas. Otras veces, se decidirá que un anuncio es complejo porque favorece las interpretaciones erróneas de sus significados (Chan \& Hogg, 2006). En este sentido, Ketelaar, Gisbergen y Bosman (2004) hablan de anuncios abiertos contraponiéndolos a anuncios cerrados. De manera que podemos hablar de anuncios abiertos, interpretables y, por tanto, complejos, y anuncios cerrados, con menor margen para la interpretación y el error y, por tanto, simples. Dado que la tarea que se solicita en nuestra investigación es evocar imágenes mentales, y que esta tarea ya es de por sí compleja, entendemos que cuanto más elaborada sea la evocación escrita, con mayor presencia de oraciones y frases unidas por conjunciones y preposiciones, será más compleja, por lo que la mayor presencia de palabras funcionales significará una mayor complejidad de las oraciones y frases, derivadas de una imagen mental más compleja.

Por todo ello, el objetivo de esta investigación es averiguar qué factores o variables influyen en la capacidad diferente que cada sujeto tiene para crear imágenes mentales, siendo las variables independientes: capacidad de viveza de imagen, sexo y la naturaleza sensorial de presentación de los estímulos: icónica, audioverbal y sonora; su forma: figurativa o no figurativa, y su grado de concreción: concreto o abstracto. La variable dependiente es la riqueza de imagen mental.

\section{Metodología}

Se ha utilizado una metodología de análisis de contenido de las palabras que intervienen en la descripción verbal escrita de las imágenes mentales evocadas por el recuerdo libre de 28 estímulos verbales, icónicos y auditivos concretos y abstractos, mediatizada por una tarea parásita de cálculo mental. El análisis de contenido que se realiza sobre la descripción de las 
imágenes mentales de la muestra permite cuantificar de modo exhaustivo las distintas categorías gramaticales que intervienen en la descripción de la imagen mental. Estos datos, previa codificación, serán susceptibles de análisis estadísticos de carácter descriptivo, con cuyos resultados podremos establecer los perfiles dominantes.

Se ha utilizado también un análisis multivariable de la varianza (Manova) entre los factores individuales que influyen en la capacidad que cada sujeto tiene para crear imágenes mentales: capacidad de viveza de imagen y sexo. Hemos diseñado una investigación experimental porque son habituales para investigaciones de esta naturaleza (Liang \& Kale, 2012).

La muestra estuvo inicialmente constituida por 150 sujetos de la Comunidad de Madrid en España, de los cuales 81 eran varones y 69 mujeres. Posteriormente se descartaron dos varones por no completar todas las pruebas, y 18 varones y diez mujeres por considerar sus pruebas nulas. $\mathrm{Al}$ final, la muestra se compuso de 120 sujetos, de los cuales 60 fueron varones y 60 mujeres. Todos los sujetos en el momento de pasar las pruebas tenían edades comprendidas entre los nueve y los 11 años. Hemos elegido a los sujetos con estas edades por considerar que disponían de capacidades óptimas para generar imágenes mentales, al poseer los siguientes dominios: 1) operaciones concretas que facilitan la formación de imágenes mentales, tanto reproductorias como anticipatorias (Vargas, 2013) y 2) conocimientos léxicos basados en definiciones verbales y en interacciones sensomotoras con el medio (Sánchez \& García-Albea, 1986). Es frecuente utilizar niños con estas edades en este tipo de investigaciones por la enorme influencia que tiene la publicidad en este periodo de vida (Aitken et al., 1987; Donovan, Jancey \& Jones, 2002; Evans et al., 2004; McCool et al., 2005; Lyons et al., 2011; Vargas, 2013).

El análisis se realizó a partir de una selección de 28 estímulos pertenecientes a tres categorías perfectamente diferenciadas. Un primer bloque está formado por imágenes publicitarias de: coche, perro, persona y libros, a las que denominaremos "imágenes de alta iconicidad"; dibujos esquemáticos de las mismas imágenes: coche, perro, persona y libros, considerados "imá- 
genes esquemáticas figurativas”, y trazos inductores, definidos como "imágenes no figurativas".

Un segundo bloque está formado por nombres, diferenciados por su grado de concreción en: nombres concretos (águila, avión, limón y cama) y nombres abstractos (dificultad, ilusión, miedo y memoria). Y, por último, un tercer bloque está formado por sonidos, clasificados en sonidos muy identificables (bebé, disparo, silbato, pájaros) y sonidos poco identificables (tijeras, papel, hojas, lavadora), según la investigación previa desarrollada para este fin.

Las imágenes de alta iconicidad fueron tomadas de anuncios publicitarios, fotografías en color sin texto escrito y con imagen de marca: Alfa Romeo para el coche, Financial Times para el periódico del modelo publicitario, Enciclopedia Larousse para los libros.

\section{Ilustración 1 \\ Ejemplo de fotografía en color de anuncio publicitario}

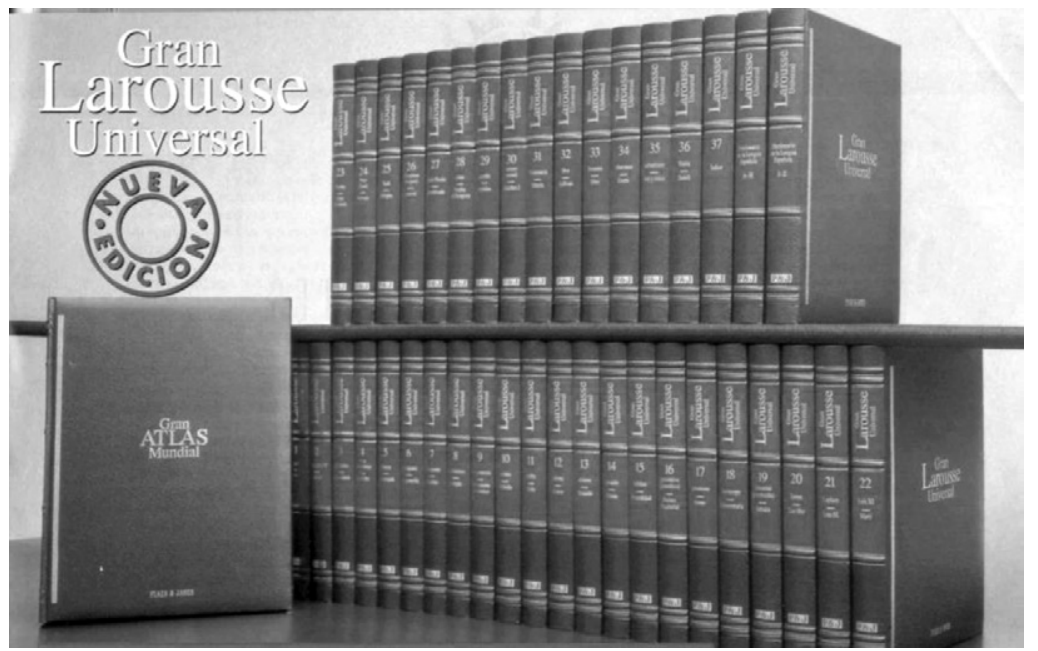

Fuente: tomada y recortada de la imagen publicitaria correspondiente.

Las imágenes esquemáticas con los mismos objetos que para las imágenes de alta iconicidad fueron realizadas con el programa Harvard Graphics y posteriormente ampliadas hasta ocupar la totalidad del tamaño del papel. 


\section{Ilustración 2 \\ Ejemplo de imagen gráfica esquemática}

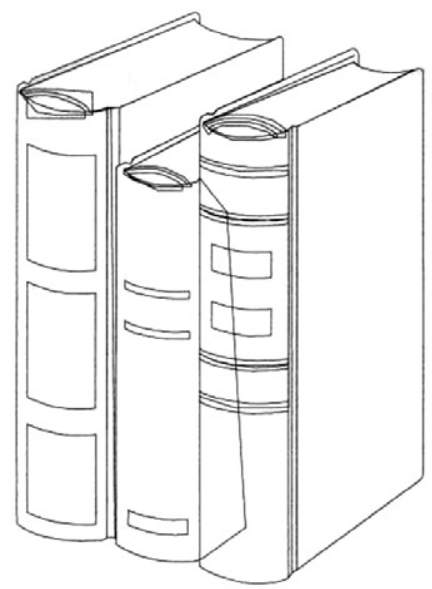

Fuente: tomada del banco de imágenes del programa Harvard Graphics.

Las imágenes inductoras no figurativas fueron construidas por los autores aplicando las herramientas del programa informático señalado: figuras geométricas (círculo, rombo y cuadrado), líneas curvas abiertas y rectilíneas, trazos, etc., a partir de los modelos de formas inductoras presentados por García (1991). El uso de imágenes no identificables ha sido ya utilizado en investigaciones publicitarias para establecer relaciones entre las imágenes surrealistas, los anuncios y su procesamiento en el cerebro (Mostafa, 2013).

\section{Ilustración 3 Ejemplo de imagen inductora}

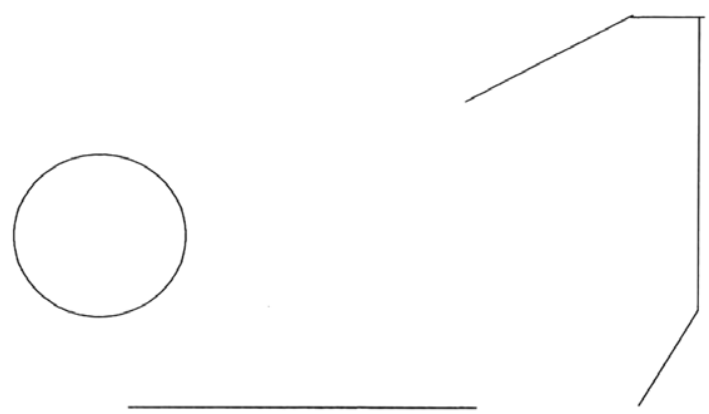

Fuente: elaboración propia, realizada a partir de los modelos presentados por García (1991). 
Las palabras fueron tomadas de la lista de 300 palabras que Campos y Astorga (1986) presentan con sus medias y desviaciones típicas en la escala concreto-abstracto (A) y en la escala desagradable-agradable (B). Los sonidos fueron seleccionados de una prueba propia de reconocimiento libre de sonidos, que consistió en un pretest para clasificar 30 sonidos de diferentes características. Se pretendía, a partir de 30 sonidos tomados de la realidad o creados, simulando sonidos reales, seleccionar cuatro muy identificables y cuatro poco identificables, con el fin de homologar los estímulos sonoros a los audioverbales y a las imágenes. Los sonidos utilizados en el pretest correspondían a las siguientes categorías naturales: papel, dinero, cristales, etc.; creados: hojas, viento, guerra, etc.; medios de transporte: barco, coche, camión, carretera, etc.; humanos: llanto de un bebé; animales: lobo, león, etc.; estéticos: piano, misa, etc. La prueba constaba de tres columnas; columna 1: clasifica numéricamente los sonidos del 1 al 30; columna 2: formula la pregunta ¿qué es?; columna 3: se pide el grado de seguridad con el que afirman lo que ponen en la columna $2 \mathrm{y}$, a su vez, se subdivide en: muy seguro, bastante seguro, seguro, poco seguro y nada seguro.

Se utilizaron como instrumentos de la investigación una prueba de respuesta libre, para obtener la descripción verbal escrita de la imagen mental previa estimulación icónica, audioverbal y auditiva sonora, mediatizada por una tarea parásita de cálculo mental, y el test Vividness of Visual Imagery Questionnaire (VVIQ), para clasificar a los sujetos en altos y bajos en capacidad para formar imágenes mentales. El cuestionario consta de dos partes, 16 ítems que se deben cubrir con los ojos abiertos y, posteriormente, los mismos ítems con los ojos cerrados.

Compartimos con Campos (1995) la valoración positiva que hace del cuestionario, por la conveniencia de sus ítems, que facilitan la generación de imágenes mentales, y por el procedimiento de puntuación, que da más puntuación a los valores pequeños y menos a los valores altos, reduciendo la tendencia a evaluación alta que pudieran tener de forma rutinaria determinados sujetos. Igualmente, tener que formarse imágenes con los ojos cerrados y abiertos permite encontrar una puntuación media que equilibre la posible disfunción determinada por la apertura de los mismos, aunque en la mayoría de los casos las diferencias sean escasas. 


\section{Procedimiento}

En primer lugar, se pasó el VVIQ de Marks para controlar la diferencia en viveza de imagen de los sujetos y así conocer la varianza en dos factores de esta variable (alto/bajo en viveza). La varianza del sexo era ya conocida por su filiación (varón/mujer). Una vez conocidos estos datos necesitábamos saber la varianza de recuerdo de imagen mental para cada sujeto según las diferentes modalidades de presentación de los estímulos para, finalmente, a través de un análisis de varianza (Manova) conocer la significatividad de los efectos de las variables controladas: sexo y viveza de imagen sobre la variable principal, el recuerdo de la imagen mental de un estímulo sonoro o visual. Se pudo comprobar lo que señala Johnson (2008: 3) sobre la importancia de la imagen visual de la publicidad en la imagen mental:

Language evokes the visual when there is no eye to see or lens to capture a picture. The visual is typically seen as the quintessence of advertising culture, and the term "image-based culture" has come to mean visual dominance in culture. Most people do, in fact, describe their consumption of advertising as looking. We say that we "look" at ads, not that we "read" them.

En segundo lugar, se solicitó la tarea de recuerdo libre de la imagen mental, es decir la restauración de la imagen mental a partir del material conservado en la memoria. De esta manera, el recuerdo era una imagen que se tenía guardada y la memoria, la capacidad mental para evocar la experiencia. Se pretendía que cada sujeto recuperara la imagen mental evocada por cada estímulo y, para evitar que el recuerdo fuera de una imagen consecutiva de memoria, se siguió este procedimiento: presentación del estímulo (20 segundos), reflexión (40 segundos), respuesta (75 segundos).

Durante los 30 primeros segundos de la etapa de reflexión se pidió a los sujetos que hicieran una operación de cálculo mental sencilla con la intención de mantenerlos distraídos y que mediara algo de tiempo entre la presentación del estímulo y el comienzo de la recuperación de la imagen mental. Se trataba de reproducir un contexto de recepción equivalente al de recepción de los anuncios publicitarios. Percy y Elliott (2005) consideran que una actividad cognitiva es la respuesta que ocurre en la mente del 
espectador cuando se procesa información que se posee con información nueva. Por ejemplo, se les presentaba el primer estímulo, "vais a escuchar una palabra, águila. Ahora haced mentalmente el siguiente cálculo, 8+7, y escribid la respuesta en el recuadro debajo del número del estímulo" (esto nos permitía comprobar que efectivamente habían realizado el cálculo mental). Después buscáis la imagen mental que tengáis de esa palabra y una vez que la tengáis podéis escribir libremente sin límite todo aquello que nos permita conocer la imagen que tenéis en la cabeza.

Antes de pasar la prueba, se les explicaba que no se trataba de un examen y que por tanto no se les iba a puntuar para la evaluación. Se pretendía eliminar las resistencias naturales a las pruebas y reducir la tensión. Este procedimiento se utilizó con los 28 estímulos que estaban organizados con los siguientes criterios: los estímulos del 1 al 24 se organizaron en primer lugar, en triadas, de tal forma que siguieran un orden que simultaneara palabra, sonido e imagen; en segundo lugar, en díadas donde a un estímulo concreto, identificable o figurativo, le siguiera otro abstracto, menos identificable o no figurativo, y en tercer lugar, en secuencias que evitaran la repetición entre estímulos cuyo contenido semántico correspondiera a la misma categoría: persona, objeto, animal, medio de transporte, etc. Cuando no fuera posible mantener los tres criterios se priorizarían en el orden presentado. En primer lugar el de soporte, en segundo lugar el de grado de analogía y en tercer y último lugar el de categoría semántica. Así, entre los estímulos 16 y 17 se priorizó la secuenciación sobre la naturaleza del estímulo y el grado de analogía, no siendo posible mantener el de categoría semántica.

Los últimos cuatro estímulos, del 25 al 28 (correspondientes a la imagen de alta iconicidad), se presentaron secuenciados para evitar romper el orden de simultaneidad de los estímulos 1 al 24 y por ser los últimos que se incorporaron. Se presentaron en el mismo orden con el que se habían presentado los estímulos figurativos esquemáticos: coche, perro, persona, libros, motivo por el cual se produjo una coincidencia de categoría semántica entre los estímulos 24 y 25 , porque se mantuvo el mismo orden de presentación para los estímulos de alta iconicidad que el que se había secuenciado para los figurativos esquemáticos. 
Una vez cumplimentados todos los protocolos se comenzó el análisis de contenido, de tal manera que se convirtieron las 3360 descripciones de imágenes mentales, con una media aproximada de seis palabras por descripción, en algo más de 20000 palabras.

\section{Resultados}

Los valores de recuerdo de las imágenes mentales, que se obtuvieron por la suma total de palabras que recordaban cada estímulo, son diferentes según la modalidad sensorial de presentación del estímulo y su grado de concreción. Sin embargo, esas diferencias no son muy amplias. Oscilan entre una banda que va desde el 19\% para la puntuación más baja (el recuerdo de la imagen esquemática de libro) hasta el 33\% para la puntuación que obtiene el valor más alto (el recuerdo de la palabra concreta águila). Esta oscilación es mayor cuando el estímulo es una palabra (figura 2) que cuando, por el contrario, el estímulo es una imagen (figura 1), y es prácticamente inexistente cuando el estímulo es un sonido (figura 3). En general se observa en las figuras 1 y 2 que las puntuaciones totales varían más cuando los estímulos son palabras concretas o imágenes de alta iconicidad (anuncios) y esquemáticas figurativas (dibujos) que cuando dichos estímulos son imágenes no figurativas (trazos), palabras abstractas o sonidos.

\section{Figura 1}

\section{Puntuaciones totales de imágenes mentales generadas por imágenes}

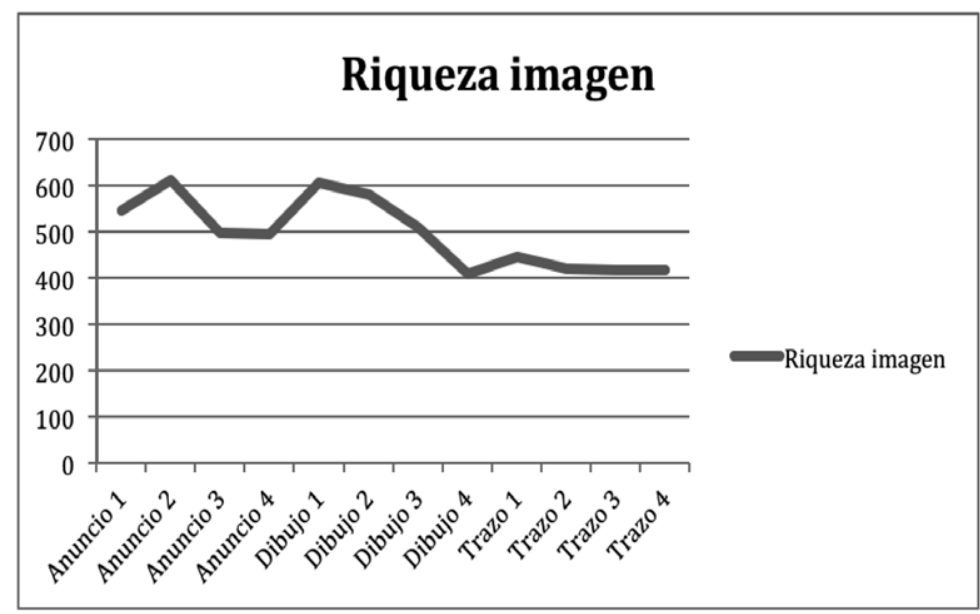

Fuente: elaboración propia. 
Figura 2

\section{Puntuaciones totales de imágenes mentales generadas por palabras}

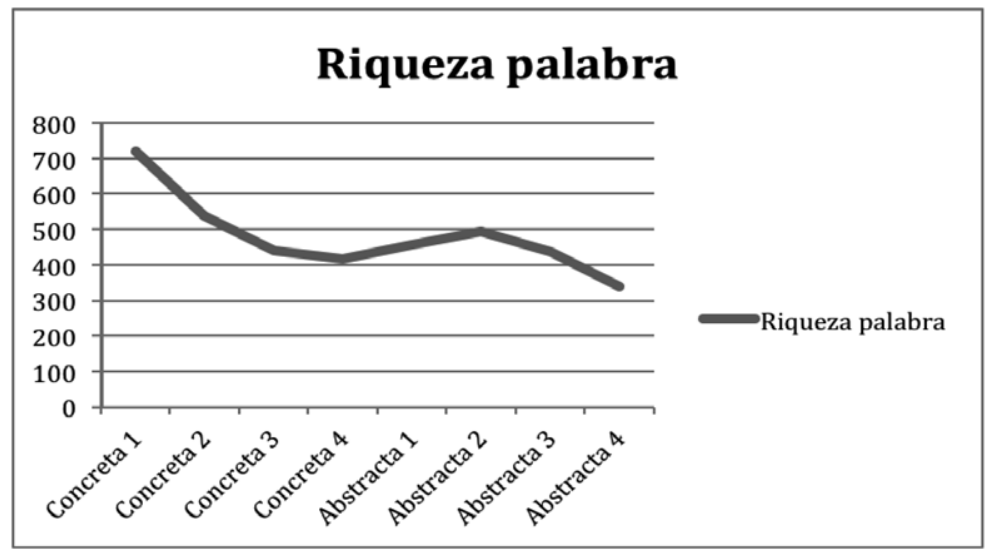

Fuente: elaboración propia.

Figura 3

Puntuaciones totales de imágenes mentales generadas por sonidos

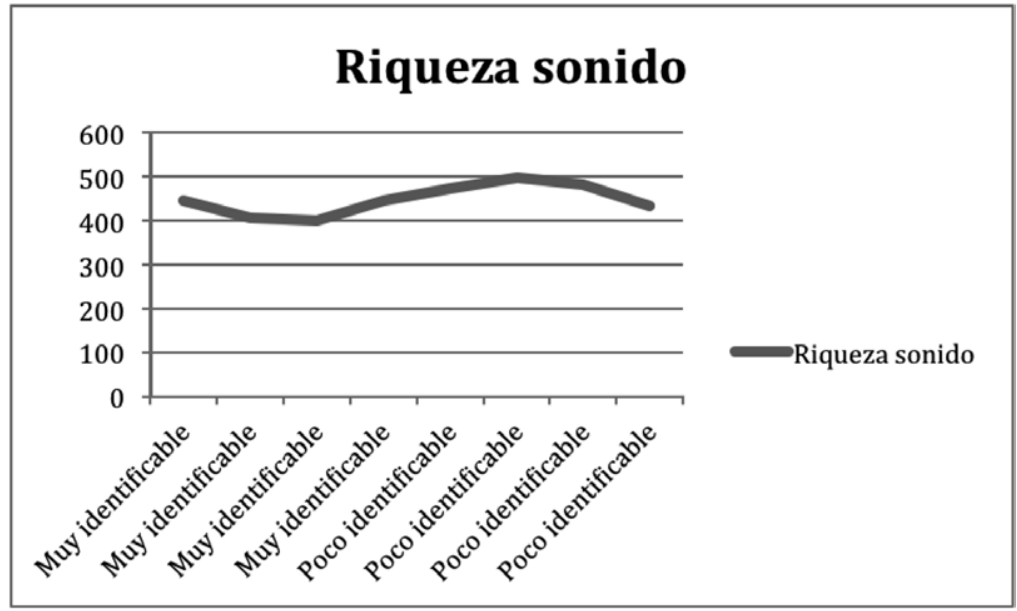

Fuente: elaboración propia.

Las medias y desviaciones típicas obtenidas en recuerdo, riqueza y complejidad de las imágenes mentales, así como en viveza de imagen mental, por los sujetos de la muestra, aparecen en la tabla 1 . 


\section{Tabla 1}

Medias (M) y desviación típica (SD) en riqueza, complejidad, recuerdo total y viveza

\begin{tabular}{|c|c|c|c|c|c|c|c|c|c|c|c|c|}
\hline & \multicolumn{3}{|c|}{ IMAGEN } & \multicolumn{3}{|c|}{ PALABRA } & \multicolumn{3}{|c|}{ SONIDO } & \multicolumn{3}{|c|}{ VIVEZA } \\
\hline & Riqueza & Complejidad & Total & Riqueza & Complejidad & Total & Riqueza & Complejidad & Total & $\begin{array}{c}\text { Ojos } \\
\text { abiertos }\end{array}$ & $\begin{array}{c}\text { Ojos } \\
\text { cerrados }\end{array}$ & $\begin{array}{r}\text { Total } \\
\text { Viveza }\end{array}$ \\
\hline M & 49,74 & 13,99 & 63,73 & 31,9 & 7,75 & 39,66 & 28,90 & 7,51 & 36,42 & 33,71 & 32,75 & 66,46 \\
\hline SD & 1,64 & 0,61 & 2,16 & 0,97 & 0,33 & 1,24 & 0,86 & 0,40 & 1,21 & 0,83 & 0,97 & 1,72 \\
\hline
\end{tabular}

Fuente: elaboración propia.

Estos primeros resultados del análisis nos permiten interpretar que existen diferencias en el recuerdo de la imagen mental achacables a los elementos que varían en los estímulos, fundamentalmente su naturaleza sensorial: icónica, audioverbal y sonora; su forma: figurativa o no figurativa, y su grado de concreción: concreto o abstracto. Esto explica la mayor variación entre las puntuaciones de recuerdo de la imagen mental cuando los estímulos son imágenes figurativas y palabras concretas, lo que nos lleva a la conclusión de que las palabras concretas y la imágenes figurativas generan imágenes mentales de alta imaginabilidad que ayudan a procesar los mensajes publicitarios correctamente y a ser entendidos, produciendo el efecto de comunicación deseado para la publicidad.

Sin embargo, a pesar de que varía el recuerdo de la imagen mental en los sujetos según la modalidad del estímulo, cuando se realizó un análisis multivariable de la varianza (Manova) para comprobar cómo los factores sexo y viveza de imagen afectaban a la variable recuerdo total de imagen mental, solo la variable viveza de imagen resultó significativa para el recuerdo de imagen mental, indistintamente de la modalidad de presentación del estímulo. Se encontró, a través de puntuaciones Lambda de Vilks, que el sexo no influye significativamente. Sin embargo la viveza de imagen influyó significativamente en el recuerdo total de la imagen $[\mathrm{F}(2,7187)=0,479, \mathrm{p}<.05]$ para todas las modalidades de presentación del estímulo: Imagen $[\mathrm{F}(1,115)$ $=3,96, \underline{\mathrm{p}}<.05]$, palabra $[\mathrm{F}(1,115)=6,85, \underline{\mathrm{p}}<.01]$, sonido $[\mathrm{F}(1,115)=7,70$, $\mathrm{p}<.01]$. Las interacciones de segundo orden no resultaron significativas. 
Después se efectuaron dos Manovas, uno con las puntuaciones de riqueza obtenidas de la suma de palabras abiertas (nombre, verbo, adjetivo y adverbio) y otro con las puntuaciones de complejidad obtenidas con las suma de palabras cerradas (preposiciones y conjunciones). Se encontró que la viveza de imagen mental no influye significativamente en las puntuaciones de complejidad de imagen mental, aunque sí influye en las de riqueza de imagen mental $[\mathrm{F}(3,7261)=0,0134, \mathrm{p}<.05]$, tanto para imagen $[\mathrm{F}(1,115)=3,92$, $\mathrm{p}=.05]$ como para palabra $[\mathrm{F}(1,115)=6,46, \mathrm{p}<.05]$ y sonido $[\mathrm{F}(1,115)=$ $10,93, \mathrm{p}<.01]$. Las interacciones de segundo orden no resultaron significativas.

\section{Conclusiones y discusión}

Se confirma lo que ya han dicho autores como Kosslyn y Koening (1992) o Denis (1984), cuando afirman que, aunque no existe ninguna imagen mental que contenga tanta información como el propio estímulo, aquellos estímulos cuya forma sea más rica en rasgos trascendentes generarán más información que aquellos que nos los tengan y resultará más fácil ver sus partes, como ocurre con los rostros bellos de la publicidad. Además, cuanto más pequeña es una imagen, resulta más difícil ver sus partes.

Al recordar un anuncio, el público activa fragmentos del anuncio, detalles que tal vez en aquel momento pasaron desapercibidos, y lo reconstruye añadiendo otros recuerdos y vivencias que tenía en su mente en el momento que procesaba el anuncio. Por eso, durante la codificación del anuncio no solo se memorizaron los rasgos más sobresalientes -logotipo, color, ilustración-, sino que se memorizaron los rasgos que seleccionamos por aprendizaje incidental (Arroyo, 2006).

Se justifica la gradación de puntuaciones en el recuerdo de imágenes mentales, que aumenta cuando el estímulo es una imagen de alta iconicidad y va disminuyendo cuando es una imagen esquemática figurativa, hasta encontrar el valor más bajo en la imagen esquemática no figurativa.

Existe una ligera diferencia entre los valores de recuerdo, que son mayores cuando los estímulos son imágenes figurativas y palabras concretas que cuando son imágenes no figurativas y palabras abstractas. Sin 
embargo, esta relación se invierte cuando el estímulo es un sonido, y sus puntuaciones totales son mayores cuando este es poco identificable que cuando es muy identificable. En definitiva, al ser los sonidos más pobres en propiedades trascendentes que las fotografías, los dibujos o las palabras, ofrecen más dificultades para discriminar, dentro de su imagen mental, dichas propiedades.

Estos resultados son congruentes con investigaciones previas que han establecido la superioridad del uso de palabras concretas en la publicidad para generar imágenes mentales que han favorecido un mayor recuerdo y actitud favorable hacia la marca, además de despertar una intención de compra (Bone \& Ellen, 1992; Wright \& Rip, 1980).

Sin embargo, otras investigaciones (Liang \& Kale, 2012) han encontrado que esta superioridad de los estímulos concretos sobre los abstractos no es homogénea en todas las culturas, de manera que los asiáticos del este, que suelen tener siempre un pensamiento concreto, generan imágenes mentales concretas aun cuando los estímulos sean abstractos; por lo que, si los mensajes publicitarios concretos pueden ser útiles para poblaciones occidentales, los mensajes publicitarios con estímulos abstractos lo pueden ser para poblaciones asiáticas del este. Luego, futuras investigaciones deberán contemplar también el factor cross cultural.

El sujeto utiliza su propia información; es decir, contextualiza, más que con cualquier otro estímulo, el recuerdo de la imagen mental. Esto justifica por qué no se mantiene la lógica de que a mayor grado de identificación del estímulo, mayor fidelidad en el recuerdo de la imagen.

Estas diferencias en la evocación escrita del recuerdo de las imágenes mentales van a mantener una diferencia individual en los sujetos, que va a depender también de su capacidad de viveza de imagen. Es decir, aunque la riqueza de la imagen mental depende de la modalidad de presentación del estímulo y del grado de concreción del mismo en nuestra muestra, los sujetos con mayor puntuación de viveza de imagen siempre recordarán sus imágenes mentales con más riqueza que los de puntuación menor, indistintamente de las otras variables. 
Esta investigación se alinea, en primer lugar, con aquellas otras investigaciones como las de García (1997), Campos y Pérez (1988b) y Vargas (2013) que no encuentran diferencias significativas a favor de ningún sexo en la capacidad para formar imágenes mentales. Tan solo cuando el estímulo es un sonido, y a través de un análisis de la varianza con un solo factor, se aprecia una ligera diferencia a favor del sexo femenino en un $39,11 \%$, frente a los varones, con un $33,73 \%$. La condición de varón o mujer no predice su éxito en tareas mnemóticas mediadas por imágenes mentales.

La viveza, obtenida a partir del VVIQ, se confirma como un buen predictor de rendimiento en evocación de imágenes mentales, indistintamente de la naturaleza de los estímulos: imagen, palabra o sonido. Se encuentra una relación entre puntuaciones en imágenes mentales y puntuaciones en el test VVIQ.

Cuando los sujetos tienen una imagen mental, la evocación escrita de su recuerdo se apoya en el uso de palabras abiertas, de tal manera que cuanto más las utilice, más rica será la imagen mental que describe. Creemos que otros estudios deberían contrastar la influencia de cada una de esas categorías gramaticales (nombre, verbo, adjetivo y adverbio) en el incremento de la riqueza de la imagen mental.

Esta investigación básica, con datos obtenidos en una muestra de niños con edades entre nueve y 11 años, aporta evidencias que deben ser utilizadas en las campañas publicitarias dirigidas a dicho público, y especialmente en las de prevención del consumo del tabaco y del alcohol en dichas poblaciones, dado el potencial impacto que la publicidad tiene a esas edades, tanto en los puntos de venta de tabaco (Donova, Jancey \& Jones, 2002) como forma de comunicación con un gran impacto en la generación de imágenes sociales (Evans et al., 2004), y en la generación de imágenes mentales de violencia, discriminación y competitividad en el cine, TV y videojuegos (Arroyo, 1999), de nuevo, especialmente en dichas edades (Aitken et al., 1987). Así como una vía preferente de generación de imágenes mentales, especialmente a través de técnicas de marketing como el product placement, con gran efectividad entre los niños y los adolescentes, como 
lo prueban estudios sobre el consumo de alcohol y reconocimiento de las marcas (Lyons et al., 2011).

\section{Referencias}

Aitken, P. et al. (1997). Children's awareness of cigarette advertisements and Brand imagery. British Journal of Addiction, 82(6), 615-622.

Alesandrini, K. L. (1982). Imagery-eliciting strategies and meaningful learning. Journal of Mental Imagery, 6, 125-140.

Arroyo, I. (2006). Investigación sobre creatividad percibida y viveza de imagen de los receptores. Madrid: Editorial Dykinson, S.L.

Arroyo, I. (1999). Cine, TV y videojuegos en la mente del niño. Cuadernos de Pedagogía, 278, 80-85

Arroyo, I. (1997). Creación de imágenes mentales según la naturaleza y las formas de los estímulos. Madrid: Servicio de Publicaciones Universidad Complutense de Madrid.

Arroyo, I., Martínez-Val, J. \& García, F. (2001). Imágenes y cultura: del cerebro a la tecnología. Madrid: Ediciones del Laberinto.

Campos, A. (1995). Twenty-two years of the VVIQ. Journal of Mental Imagery, 19, 129-131.

Bone, P. F. \& Ellen P. S. (1992). The Generation and Consequences of Communication-evoked Imagery. Journal of Consumer Research, 19, 93-104.

Campos, A. \& Astorga, V. M. (1986). Valores de concreción y emotividad de palabras españolas. Cognitiva, 2, 99-110. 
Campos, A. \& Pérez, M. J. (1988a). Visual elaboration scale as measure of imagery. Perceptual and Motor Skills, 66, 411-414.

Campos, A. \& Pérez, M. J. (1988b). Vividness of movement imagery questionnaire: Relations with other measures of mental imagery. Perceptual and Motor Skills, 67, 607-610.

Chan, T. W. \& Hogg, M. K. (2006). Copyless ads: The impact of complex advertising images on attitude toward the advertisement. European Advances in Consumer Research, 7, 51-58.

Denis, M. (1984). Las imágenes mentales. Madrid: Siglo XXI.

Diller, A. M. (1991). Cohérence métaphorique, action verbale et action mentale en français. Communications, 53, 209-227.

Donovan, R. J., Jancey, J. \& Jones, S. (2002). Tobacco point of sale advertising increases positive brand user imagery. Tobacco Control, 11(3), 191-194.

Evans, W. et al. (2004). Social Imagery, tobacco indpendence and the truth. SM campaign. Journal of Health Communication, 9(5), 425-441.

García, F. (1991). Estrategias creativas. Madrid-Barcelona: Vicens VivesM.E.C.

García, F. (1997). La imagen de los locutores de radio. En AA. VV., Radio fin de siglo (45-72). Sevilla: Ediciones Trípode.

Giambra, L. \& Grodsky, A. (1991). Aging, imagery and imagery vividness in daydreams: Cross-sectional and longitudinal perspectives. En Kunzendorf, R. G. (Ed.), Mental imagery (23-33). Nueva York: Plenum Press.

Johnson, F. L. (2008). Imaging in advertising. Verbal and visual codes of commerce. Nueva York y Londres: Routledge. 
Ketelaar, P. E., Gisbergen, M. S. \& Bosman, J. A. (2004). Open and closed advertisements: Moderating effects of comprehension on appreciation. En Neijens, P. et al. (Eds.), Content and media factors in advertising (51-62). Ámsterdam: Het Spinhuis Publishers.

Kosslyn, S. M. \& Koenig, O. (1992). Wet Mind: The New Cognitive Neuroscience. Nueva York y Ontario: Free Press . Maxwell Macmillan.

Liang, B. \& Kale, S. H. (2012). Cultural differences in imagery generation: The influence of abstract versus concrete thinking. Journal of Business Research, 65, 333-339. Doi: 10.1016/j.busres.2011.04.010

Llorente, C. (2013). Tippexperience: el ornato como fuente creativa para la construcción de formatos publicitarios innovadores en YouTube. Icono 14, 11(1), 71-98. Doi:10.7195/ri14.v11i1.514

Lyons, A. et al. (2011). Alcohol imagery and branding, and age classification of films popular in the UK. International Journal of Epidemio$\log y, 40(5), 1411-1419$. Doi: 10.1093/ije/dyr 126

Marks, D. F. (1989). Bibliography of research utilizing the Vividness of Visual Imagery Questionnaire. Perceptual and Motor Skills, 69, 707-718.

McConkey, K. M. \& Nogrady, H. (1986). Visual elaboration scale: Analysis of individual and group version. Journal of Mental Imagery, 10, 37-46.

Mccool, J. P. et al. (2005). The infuence of smoking imagery on the smoking intentions of young people: Testing a media interpretation model. Journal of Adolescent Health, 36, 475-485.

Mckelvie, S. J. (1986). Effects of format of the Vividness of Visual Imagery Questionnaire on content validity, split-half reliability, and the role of memory in test-retest reliability. British Journal of Psycho$\log y, 77,229-236$. 
Morrison C. M., Ellis A. W. \& Quinlan, P. T. (1992). Age of acquisition, not word frequency, affects object naming, not object recognition. Memory \& Cognition, 20(6), 705-714.

Mostafa, M. (2013). The persistence of memory: An fMRI investigation of the brainprocessing of Surrealistic imagery in advertising. Journal of Marketing Communications, 19(5), 341-359.

Paivio, A. (1971). Imagery and verbal processes. Nueva York: Holt, Rinehart \& Winston.

Paivio, A. \& Harshman, R. (1983). Factor analysis of a questionnaire on imagery and verbal habits and skills. Canadian Journal of Psycho$\log y, 37,461-483$.

Percy, L. \& Elliot, R. H. (2005). Strategic advertising management. Oxford: Oxford University Press.

Robles, S. (2004). Realce y apelación en el lenguaje de la publicidad. Madrid: Arco/Libros.

Rossiter, J. R. (1988). The Increase in Magazine Ad Readership. Journal of Advertising Research, 28(5), 35-39.

Sánchez, M. (2008). Sonido envolvente 5.1: una posible solución a la crisis publicitaria en España. Madrid: Dykinson.

Sánchez, R. \& García-Albea, J. (1986). Dos vocabularios: diferencias computacionales en el estudio del lenguaje. En Siguán, M. (Ed.), Estudios de psicolingüística (87-103). Madrid: Pirámide.

Schroeder, M. (2008). Being for: Evaluating the semantic program of expressivism. Oxford: Oxford University Press.

Sharps M. \& Price J. L. (1992). Auditory imagery and free recall. Journal General Psycholy, 119(1), 81-87. 
Thompson, V. \& Paivio, A. (1994). Memory for pictures and sounds: Independence of auditory and visual codes. Canadian Journal of Experimental Psychology/Revue canadienne de psychologie expérimentale, 48(3), 380-398. Doi: 10.1037/1196-1961.48.3.380

Van Loon-Vervoorn, A. \& Van Der Ham-Van Koppen, M. (1988). The importance of age of word acquisition for imageability in word processing. En Denis, M. et al. (Eds.), Cognitive and Neuropsychological Approaches to Mental Imagery (99-107). Dordrecht y Boston: Martinus Nijhoff Publishers.

Vargas, L. (2013). Publicidad en niños y conjuntos de consideración de marca basados en la memoria. Cuadernos.Info, 32, 89-100. Doi: 10.7764/cdi.32.495

Wright, P. \& Rip, P. C. (1980). Product class advertising effects on firsttime buyers' decision strategies. Journal of Consumer Research, 7, 176-188.

Zvyagintsev, M. et al. (2013). Brain networks underlying mental imagery of auditory and visual information. European Journal of Neuroscience, 37(9), 1421-1434. Doi: 10.1111/ejn.12140 